\title{
INDICADORES SOCIALES PARA LA CiUdADANÍA
}

\author{
Por: Ana Maria Quiroga
}

RESUMEN

l l fenómeno de la construcción de ciudadanía en los países llamados periféricos, como es el caso de América Latina, es tratado en este documento desde las configuraciones que dicho fenómeno ha asumido en estas sociedades; en ese sentido muestra como en la experiencia Latinoamericana surgen nuevas demandas, nuevos sujetos, nuevas formas de movilización, por tanto nuevas miradas e indicadores para su análisis.

La reflexión está planteada también desde la construcción del ejercicio profesional del Servicio Social, por tanto de su acción profesional, en esta perspectiva se señala una tarea precisa a la cual contribuir: la construcción de nuevos indicadores de ciudadanía (la ampliación de la ciudadanía en el mundo contemporáneo) para con esas nuevas medidas proponer y lograr la meta de la construcción de las sociedades que sería lo que caracterizaría al siglo XXI.

\section{INTRODUCCIÓN}

Hoy, pensar la ciudadanía implica comprender, por lo menos, cuatro movimientos que orientarán mi exposición aqui. Una comprensión que pasa, en primer lugar, por retomar, aúnque rápidamente, los conceptos que, a través de la experiencia occidental, estuvieron en las bases, e idearon modelos históricos de ciudadanía en las diferentes realidades, cuya expresión estuvo vinculada a la trayectoria de los países centrales.

En segundo lugar, pasa por analizar las configuraciones asumidas por la ciudadanía en las realidades dichas periféricas como es el caso de América Latina, en general, y de Brasil, en especial. En éstas, aunque refereridas a conceptos y modelos más generales, construidos por las tradiciones del pensamiento occidental, su materialización histórica no se efectivó de la misma forma. Al contrario, tuvimos un recorrido de modelos de ciudadanía considerados "imperfectos" donde apenas una parte de la población fue considerada, y tratada, como ciudadana. 
En tercer lugar, es necasario examinar los principales dilemas puestos al concepto y a la realidad de la ciudadanía por la dinámica de la mundialización de la economía, de la política y de la cultura, así como las perspectivas que surgen para pensar hoy esos procesos. Estos piden la incorporación de nuevos segmentos sociales, construyen nuevas demandas, articulándose en torno de nuevas formas de mobilización colectiva, y exigiendo, obviamente, nuevas miradas e indicadores para su análisis.

El cuarto elemento de nuestra reflexión será por tanto, el exámen de los parámetros que, desde nuestro punto de vista, deben ser contemplados en esa nueva mirada de tal forma que, como sujetos sociales y como profesionales de Servicio Social, podamos captar, comprender y contribuir con las nuevas tareas de construcción de sociedades contemporáneas más justas y solidárias.

\section{Una Rápida Incursión en la Tradición Occidental}

El concepto de ciudadanía posee una larga trayectoria en el pensamiento filosófico y político-social que, escaparia a los límites de esta comunicación su reconstitución tanto en téminos conceptuales y/o de las sucesivas formas asumidas a través de la historia ocidental. Entretanto, de esa trayectoria, algunos elementos que fundaron el concepto merecen ser retomados como forma de iluminar el análisis del tiempo presente, o sea, el de un mundo que no se reconoce más en los parámetros económico-sociales y ético-políticos que fundamentaron las sociedades antiguas y modernas. Así, las dimensiones del individuo y sus intereses, del bien común o de la res publica, y del pertenecer a la comunidad están en la base de las concepciones de ciudadanía que, desde los antiguos, pasando por las concepciones de los modernos, alcanza el debate de las vicisitudes de la ciudadanía en el mundo contemporáneo.

La construcción de la idea de la autonomización del individuo, sus intereses y su liberación de las cadenas que lo sometían a comunidades exclusivas y autoreferidas, se constituye en uno de los elementos fundamentales de la perspectiva de la modernidad. Articuladas a ella fueron construidas nociones de derechos, cuya titularidad marca la esencia de las perspectivas más liberales de ciudadanía. Así, la ciudadanía como el acceso a los derechos reconocidos por la estructura jurídico-política, donde se prioriza el individuo y sus intereses, está presente en las nociones que van desde Kant hasta Rawls y marcan los modelos de civismo, de constitución del sujeto y, posteriormente, los modelos de protección social de las sociedades capitalistas, con énfasis en aquellas de tradición liberal anglosajona. Una segunda perspectiva que funda el concepto de ciudadanía, presente desde el 
republicanismo clásico pasando por Maquiavel, Montesquieu y retomada en la contemporaneidad por autores como Hanna Arendt, se distingue de la concepción anterior, en la medida en que prioriza el bien comun como virtud cívica. Aqui la res publica, la supremacía del bien colectivo y la disponibilidad del ciudadano para concesiones individuales en favor de la colectividad constituye la marca de la noción de ciudadanía. Fundamentando toda una noción de espacio público, esa perspectiva dará, posteriormente, las bases para la construcción de modelos de acción de los estados modernos y de sus sistemas de protección social. En ellos, en nombre de la justicia, de la solidaridad social y como resultado de las luchas de nuevos sujetos constituidos como ciudadanos, fueron erigidas instituciones republicanas, leyes y derechos políticos y sociales que caracterizaron las tradiciones de las social-democracias europeas.

Un tercer elemento, relacionado con el anterior pero que no se confunde con él, es la noción de pertenecer a una comunidad política. En esta concepción, la visión comunitaria de la ciudad de los antiguos, se transforma en la versión moderna de nación para construir un concepto de ciudadanía fundamentado en el reconocimiento recíproco de los individuos y en la atribución de derechos por su condición de identidad y de pertenencia a una comunidad de iguales. Algunos autores, como Turner (1990) indicarán que la expresión-modelo de esa perspectiva es la concepción de ciudadanía alemana cuyos contornos del pertenecer se definian en torno a la raza germánica. De cualquier forma, uno de los elementos importantes de la dimensión comunitaria de ciudadanía es la identidad de origen y destino comunes entre los sujetos participantes, identidad que es accionada por las instancias de poder, en diferentes niveles y con distintos grados de intensidad, para alcanzar la sumisión y sacrificios individuales en favor de los intereses de la colectividad.

Evidentemente, esos tres elementos, que fundamentan concepciones distintas de ciudadanía, no se encuentran en ninguna experiencia histórica en "estado puro". Su materialización es más una cuestión de dar mayor o menor énfasis a cada uno de ellos. Así, la titularidad de derechos básicos, las nociones de justicia y solidaridad y la identidad colectiva terminaron constituyéndose en los pilares sobre los cuales fue construida la condición de "ser ciudadano", sobretodo en los países con más tradición socio-política, y también como referencias para pensarse la ciudadanía y sus desafios en el mundo contemporaneo.

Finalmente, considerando la relación entre ciudadanía y políticas sociales - objeto priorizado en los debates de esta mesa - es importante una referencia, aunque 
breve, a la obra de Marshall (1965) por su importancia en la sistematización de los tipos de ciudadanía y su desarrollo en las sociedades modernas. Aqui no nos referiremos tanto a su clásica distinción entre ciudadanía y derechos civiles (vinculados al ejercicio de las libertades individuales) y políticos (vinculados a la participación o a la representación en las decisiones políticas), y su desarrollo en la historia europea, sino en su perspectiva de ciudadanía social. Definiendo la ciudadanía social como el conjunto de derechos y obligaciones que posibilitan la participación igualitaria de todos los miembros de una comunidad en sus padrones básicos de vida, Marshall enfatizará que esa dimensión es la que permitirá el compartir la herencia social y los modelos de vida civilizada que las colectividades lograron alcanzar. Además, la ciudadanía social - en cuya construcción son fundamentales los sistemas educacionales, los servicios de salud y de asistencia social - se constituye en un elemento básico e indispensable para mantener la cohesión e integración social considerando las desigualdadades creadas por las economías de mercado. De esta forma, se podría decir que la visión de Marshall sobre ciudadanía, aunque fuertemente marcada por las perspectivas liberales, contiene y combina las tres visiones anteriores. Además, en las experiencias reales, de acuerdo con las características del proceso históricopolítico de cada una de las sociedades y con distinto énfasis, aparecen mezclados elementos de esas tres tradiciones.

\section{La Experiencia Latinoamericana}

En América Latina en general, y en Brasil, en particular, la construcción histórica de la ciudadanía se dio de forma más problemática. En la región, el proceso de colonización se impuso por el poder de las armas y por el miedo, y el mantenimiento del poder colonial fue sustentado por grupos oligárquicos locales y por sus relaciones con las metrópolis. La gran mayoria de las poblaciones, constitutivas de las naciones (mayorias indígenas, negros esclavos y sus descendientes, poblaciones mestizas y campesinas), ni siquiera eran consideradas como formando parte de la esfera de la humanidad y, consecuentemente, asumidos como individuos con

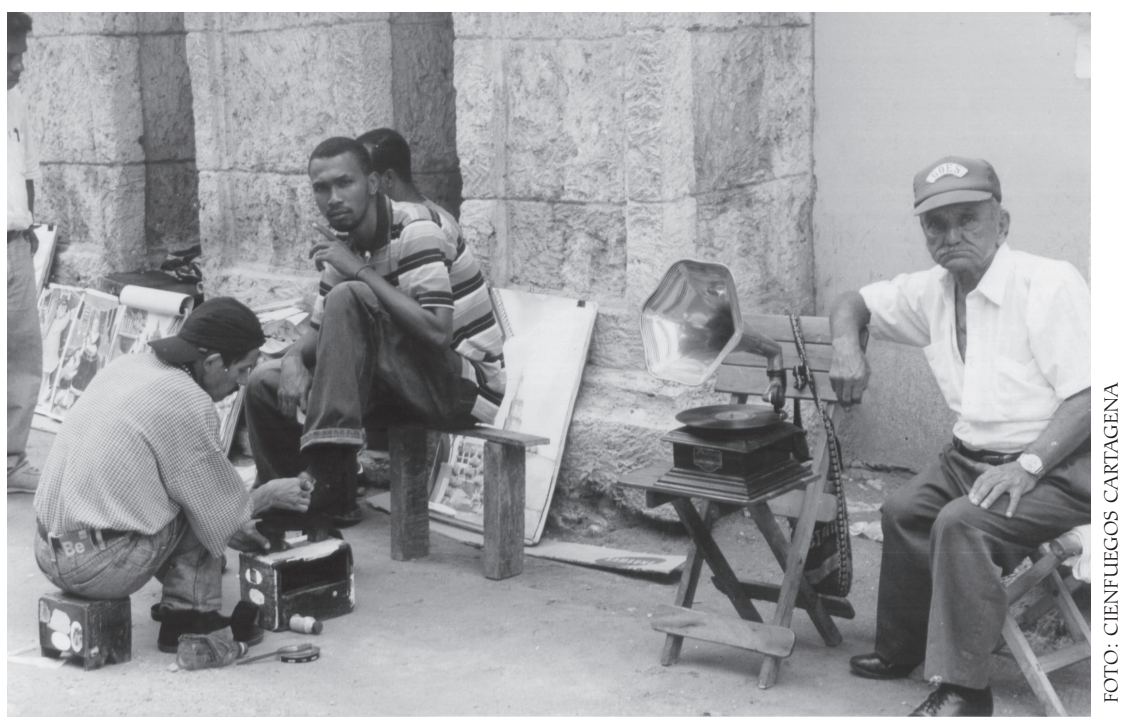


intereses a respetar.

En la formación de las sociedades nacionales latinoamericanas, post-colonia, y en el posterior ingreso a lo moderno, se mantiene una lógica excluyente de ciudadanía, donde apenas algunos segmentos - basicamente los vinculados al trabajo asalariado urbano - fueron los considerados incluidos. Así, fue por el trabajo, y más especificamente por el vínculo a determinadas categorías de empleos, que otros sectores sociales comenzaron a ser considerados portadores de derechos, principalmente los de carácter social. Mientras tanto, la forma asalariada no fue, en el continente, un horizonte general para las poblaciones urbanas y mucho menos para las rurales. Además, aunque con diferencias en las trayectorias históricas nacionales latinoamericanas, el poder político y las elites que lo sustentaban, se mantienen resistentes al reconocimiento de la autonomia de los movimientos de las clases trabajadoras, lo cual generó un tipo de "ciudadanía doblemente imperfecta": además de no incorporar a los diferentes segmentos sociales, a los incluidos se les reconocian derechos sociales pero sin autonomía ciudadana.

Por otro lado, el Estado en América Latina, responsable por gran parte de las iniciativas de modernización y extensión de medidas en el campo de los derechos y de la ciudadanía, en varios momentos autoritarios expresó, de forma mítica, "la voluntad general", movilizando la fidelidad del vínculo pueblo/jefes políticos o caudillos. Esto reforzó, de un lado, la naturaleza autoritária de nuestras experiencias republicanas, y de otro, el atraso de la internalización de una cultura cívica y de derechos a nivel de la sociedad.

Evidentemente, en las diferentes tradiciones occidentales, cupo al Estado un papel fundamental en lo que se referiere a la implementación y respecto de las garantias de la ciudadanía en cualquiera de sus dimensiones. Entretanto, el nivel de igualdad y de desarrollo del proceso de autonomización de los sujetos; el grado de expansión e incorporación social de las concepciones de Justicia y de Bien Comun; la fuerza, o la fragilidad, de las sociedades civiles y de los movimientos organizados, configuraron distintos escenarios para la estructuración de la acción estatal y para el comportamiento de sus instituciones jurídico-políticas.

En el caso de América Latina, la desigualdad de las sociedades pre-industriales, a pesar de la incorporación económica, social y política de algunos segmentos de trabajadores urbanos, se radicaliza con el industrialismo permaneciendo fuerte dependencia y tutela tanto en la relación pueblo-elite como entre trabajadoresorganizaciones sindicales y Estado, lo que significó una débil autonomización 
de los sujetos sociales. Por otro lado, las concepciones de justicia y bien común se vieron limitadas a determinados grupos de los sectores medios, intelectuales y líderes religiosos y de trabajadores, que intentaron, como sociedad civil, presionar por la democratización de los regímenes republicanos y por la constitución de instituciones y garantias ciudadanas.

Entretanto, gran parte de la población de los diferentes Estados-Nación permanece manejándose en el interior de las redes familiares y comunitarias de relaciones sociales en las cuales se siente identificada y reconocida como individuo. Además, en el interior de esos grupos son construidos mecanismos de garantía de un padrón básico de sobrevivencia y bienestar, fuera de -o a penas tocando tangencialmente- las instituciones del mercado formal y la institucionalización de los espacios públicos. De esta manera, esos segmentos fueron construyendo, a través de la familia, de las comunidades y del asociativismo confesional o laico, un modelo de ciudadanía social más cercano a las tradiciones comunitarias. Ese modelo, fuerte en el medio rural latinoamericano, fue llevado para las ciudades acompañando y viabilizando los procesos migratorios y la formación de las propias metrópilis de la Región.

Así, la entrada de América Latina en el concierto de las naciones modernas tuvo que enfrentar cuestiones derivadas de la constitución de repúblicas sin democracia y de democracias sin incorporación social. En éstas, amplios sectores sociales, tanto urbanos como rurales, se mantuvieron al margen, tanto del mercado formal de trabajo, como de la esfera pública de los derechos y benefícios sociales inherentes a las concepciones y a las condiciones de ciudadanía, hasta entonces establecidas en los países centrales. De cualquier modo, a través del siglo XX, bajo distintas presiones internas y externas, las diversas naciones latinoamericanas fueron creando y perfeccinando, aunque en niveles meramente formales, su cuadro jurídico-político de derechos civiles, construyendo sus estructuras institucionales de acceso y ejercicio de derechos políticos, y sus sistemas de protección social. En todos ellos, el Estado asumió centralidad y la identidad nacional fue frecuentemente accionada.

En los últimos 20 años, en casi todo el continente, después de dictaduras más o menos largas, son reinstalados los procesos democráticos. Con ellos se reinstalan los rituales democráticos de elecciones libres, de organizaciones partidarias y debates públicos. Varias de las constituciones nacionales son reformuladas buscando ampliar la responsabilidad del Estado en la implementación y mantenimiento de derechos y políticas sociales necesarias para enfrentar una pobreza y una desigualdad social abismal que, estando 
arraigadas en las estructuras históricas latinoamericanas, fueron radicalizándose durante los períodos autoritarios y asumiendo formas cada vez más agudas.

\section{Los Desafíos de la Ciudadanía en el Mundo Contemporaneo}

Hoy, la comprensión de la ciudadanía y la búsqueda de nuevos rumbos se tornó extremamente compleja, una vez que sus dimensiones y sus prácticas comenzaron a ser confrontadas por múltiples fenómenos y procesos. Si hasta la mitad del siglo XX, la situación de los países centrales y periféricos se distinguia radicalmente, nos lanzamos al siglo XXI con una serie de tendencias e impactos comunes. En todo el mundo occidental, para focalizar un universo más conocido por nosotros, casi que podríamos decir que la ciudadanía hoy se ve desafiada a una ampliación y a una estructuración en moldes distintos a los que fueron concebidos en sus formas más clásicas.

En primer lugar, la mundialización de la economía, que alcanza de forma planetária las finanzas, el comercio, la producción, los servicios y los sistemas de información, ha generado enormes transformaciones en las relaciones internacionales y en la estructura interna de los diferentes países. Si de un lado, se puede decir que aumentaron las posibilidades de bienestar (por la ampliación y diversificación de los items de consumo puestos a disposición de las diferentes poblaciones), de otro, las sociedades se ven confrontadas con altos niveles de inestabilidad laboral e inseguridades socio-económicas, culturales y subjetivas. En este contexto, surgen y ganan relieve fenómenos tradicionalmente considerados como característicos de los países del tercer mundo: desempleo, pobreza, exclusión social, conflictos étnicos, procesos migratorios, además de enormes incertidumbres en relación al destino y a los horizontes para su juventud.

En segundo lugar, la planetarización de las instancias de decisión y gestión política con la actuación de organizaciones transnacionales e instituciones supranacionales (parlamentos, consejos) estipulan modificaciones en las reglas y procedimientos de gobernabilidad y en los sistemas políticoadministrativos de cada nación. Con esto, los Estados Nacionales se ven obligados no sólo a integrar un nuevo diseño de las relaciones externas, como a modificar sus constituciones y métodos de acción interna (reduciendo su estructura, sus regulaciones, sus políticas de intervención y, principalmente, sus sistemas de protección). Todo esto repercute, obviamente, en las relaciones con su población. En un cierto sentido, la transnacionalización de las gestiones políticas contribuye para distanciar el ciudadano común de la participación en 
la vida pública, reduciendo la posibilidad de movilización de las poblaciones para proyectos nacionales y locales en los cuales ellas se sientan incluidas. Es importante destacar también, que los Estados Nacionales, a pesar de estar más reducidos en sus posibilidades de actuación, permanecen como los responsables por la administración de sus conflictos internos, teniendo que conciliar, las contradicciones entre operar políticas macroeconómicas restrictivas y recesivas y atender demandas sociales y políticas derivadas de, y necesarias para, la democracia y el desarrollo de sus pueblos.

En casi todos los países y en diferentes niveles (central, regional, local), se viven procesos vinculados a las reformas del Estado. Éstas inciden fuertemente sobre la actuación en el área de los servicios públicos, de la seguridad y de las demás políticas y programas sociales. En todas ellas han sido adoptados modelos de financiamiento y gestión (total o parcialmente) privatizados lo que genera modificaciones, frecuentemente profundas, en su perfil de atención. Además, la participación de otros actores individuales y organizacionales en las parcerías o en la sustitución del Estado, intrudujeron institucionalidades más complejas en las decisiones y ejecuciones de las políticas. Es importante destacar que todas esas áreas son fundamentales dentro de la perspectiva de la ciudadania, una vez que sobre ellas, fueron construidos campos, más o menos amplios, de derechos. Además, por representar una fuerte relación con las necesidades de la población, esas áreas representan también un escenario donde, de forma más nítida, la población evalua los poderes públicos, sintiéndose o no por ellos atendida o asistida.

En tercer lugar, la mundialización de la cultura realizada a través de la acción de los sistemas de información, de la expansión de la media electrónica, de toda la producción de la industria cultural y de publicidad, de la ampliación del turismo real o virtual y de los desplazamientos poblacionales. Todos esos procesos, atravesando el mundo contemporaneo, han puesto en contacto pueblos, ideas y valores, hábitos y modos de vida, modelos de consumo y sensibilidades. Aliadas a las demás transformaciones, las operadas a nivel de la cultura, han desgastado las bases de apoyo de las concepciones de Nación e Identidad Nacional tan importantes en la construcción de las perspectivas de la ciudadania.

A esas macrotransformaciones, otras alteraciones socio-culturales importantes han generado repercusiones en el campo de la ciudadania. La primera de ellas se refiere a las familias, que principalmente, en el caso de América Latina, representaron, y en cierto sentido, todavia representan, fuentes informales de 
bienestar social. Fenómenos como unidades familiares menores, el trabajo femenino fuera del hogar, la vulnerablidad económica de los hogares fruto de la inestabilidad laboral y de los desempleos constantes, una mayor autonomia de los hijos en relación a valores y comportamientos de los padres, han transformado a las familias en unidades menos consensuales. En ellas, los modos más tradicionales de dividir responsabilidades y los enfrentamientos generacionales y en las relaciones de género, han ampliado los conflictos y tornado inviables o insoportables las responsabilidades domésticas referidas al bienestar de sus miembros.

En relación a las comunidades, diversos estudios en América Latina han demostrado que factores externos, como la violencia urbana, los vínculos de carácter religioso, y hasta la lucha desesperada de las familias por la sobrevivencia, estan representando estímulos poderosos a la fragmentación comunal y a una radicalización del individualismo. Con esto se debilita una cierta cultura comunitaria existente principalmente en los contextos populares, reduciendo el papel de los vecinos como base de las organizaciones colectivas de carácter local.

Todos estos factores vinculados a las transformaciones políticas y sociales del mundo globalizado, si por un lado, desencadenan problemas y desafíos en las bases sobre las cuales se sustentaban las configuraciones anteriores de la ciudadanía, por otro, abren toda una serie de otras posibilidades:

- El surgimiento de nuevos actores sociales cuya presencia y fuerza en la sociedad no se fundamenta en el vínculo productivo o de clases - en los moldes del pacto social moderno - sino en otras bases relacionadas a las

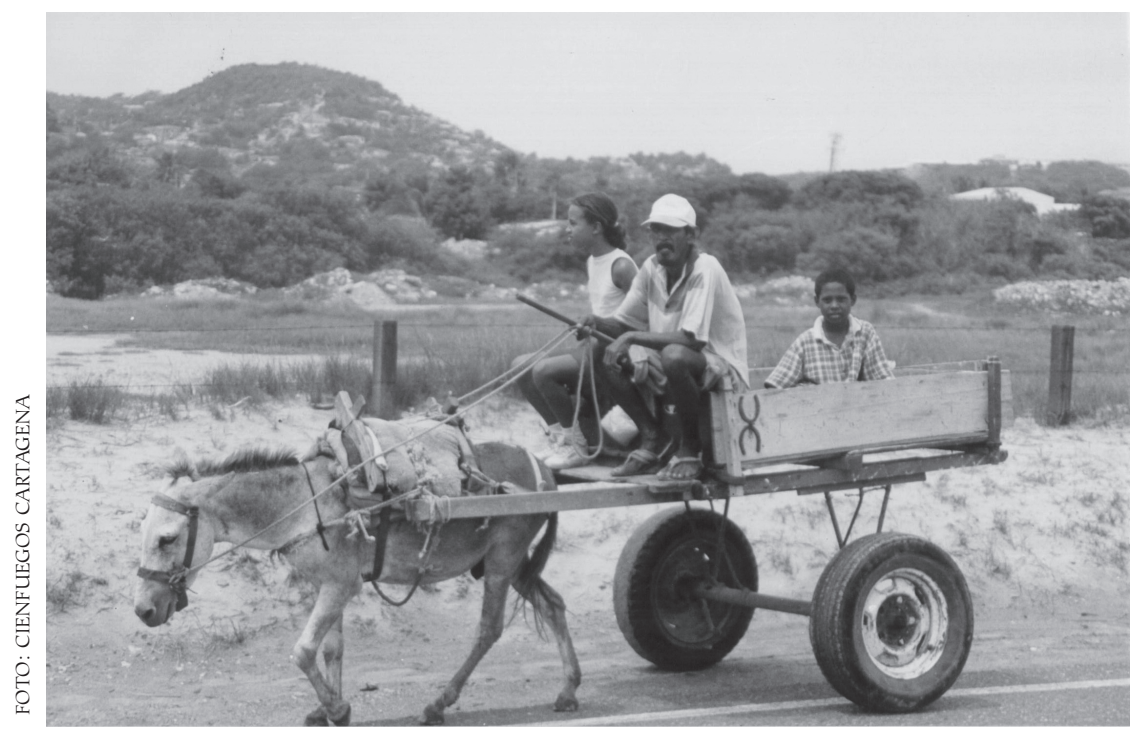
etnias (negros, indígena); a los desplazamientos poblacionales de grupos con orígenes nacionales comunes (los migrantes e inmigrantes); a los grupos etários (jovenes, idosos), o a la condición de género y de orientación sexual (mujeres y grupos homosexuales); y a las propias opciones religiosas. Esas categorias expresan distintas posibilidades de relaciones sociales y de reconocimiento más allá del 
pertenecer al cuerpo político de una nación o a la constitución de una única lealtad en torno de la identidad nacional. A partir de estas otras posibilidades y lugares, nuevas demandas son integradas a la agenda pública y los individuos postulan nuevos derechos colectivos: a la diferencia, a la legitimidad y al respeto de sus creencias, condiciones y modos de vida diferentes.

- La explosión de nuevas demandas, ya sean vinculadas con la garantía del lugar económico, social y político de esos grupos en el contexto de las relaciones sociales, ya sean dirigidas para la eliminación de mecanismos y procesos excluyentes y discriminantes de su presencia y participación social. Esas demandas destacan las condiciones desfavorables en relación al empleo, a la discriminación social y a las segregaciones vividas por diferentes segmentos sociales. Además, otras dimensiones de la vida social, de las creencias y de las subjetividades son politizadas y conducidas para el espacio público.

- La aparición de nuevas formas de expresión y movilización colectiva que complementan, o sustituyen, las antiguas organizaciones y formas institucionalizadas de manifestación de la voluntad política y de la representación en los sistemas jurídico-políticos de los diferentes países. Esas nuevas formas aparecen en virtud tanto del distanciamiento y del desencanto con los mecanismos y procesos políticos tradicionales como por la necesidad de buscar formas con las cuales los sujetos tengan mayor identificación. En ese sentido, adquieren relevancia manifestaciones políticas expresadas a través de la cultura y de los eventos culturales. La propia reafirmación de los modos de vida de las poblaciones y sus grupos internos pasó a constituirse en forma de manifestación política, lo que tiene efectos contradictorios de avances y retrocesos en la perspectiva de una ciudadania más amplia. De cualquier forma, la cultura aparece como una instancia potencial de constitución de "links", no sólo en el interior de los diferentes segmentos sociales, como entre grupos sociales separados por las desigualdades económicas y sociales. Además, otras propuestas de manifestación y movilización social están igualmente colocadas en los escenarios nacionales e internacionales. Ellas son representadas, a nivel internacional, por el surgimiento y la resignificación del fenómeno de las multitudes, estudiadas por autores como Marazzi (2002) a partir de las recientes manifestaciones en contraposición a las Conferencias Internacionales o de Organismos Multilaterales (FMI, OMC, Grupo de los 7 , etc.). A nivel interno de los países, han crecido igualmente las manifestaciones colectivas de inconformidad y repudio que agrupan, en las calles, diferentes sectores de la población. En estas manifestaciones 
son construidos, colectivizados y politizados nuevos símbolos e íconos hasta entonces pertenecientes a esferas cotidianas y privadas de la vida socio-cultural. Finalmente, es importante destacar otras dos nuevas formas de movilización de colectivos de individuos/ciudadanos. Aquellas formas viabilizadas por las redes de información que, acortando espacios, interconectan individuos, grupos y organizaciones en función de intereses temáticos, causas, demandas y perspectivas de lucha en comun. Además de éstas, los medios de comunicación colectiva, por su poder de dar visibilidad y emoción a las cuestiones sociales y políticas, asumen un papel fundamental en el campo de la ciudadanía, constituyendo, en las sociedades contemporáneas, una de las instancias, por exelencia, de actuación de presiones de opinión pública. Evidentemente, como medios de expansión de la ciudadanía, la utilización tanto de las infovias como de los medios de comunicación se enfrentan con las contradicciones vinculadas a las enormes desigualdades de acceso a esos medios, sea entre diferentes países, sea entre los grupos sociales internos, principalmente los más desfavorecidos.

- La emergencia y fortalecimiento de nuevos mediadores - individuos, grupos profesionales y organizaciones - que, a partir de la radicalización contemporanea de las diferencias y desigualdades socio-culturales, han actuado en los procesos de interacción, comunicación y negociación entre grupos sociales y esferas de la sociedad y del poder político. De hecho, si se puede decir que hoy el mundo dispone de poderosos aparatos tecnológicos con capacidad de acortar espacios y tiempos estableciendo flujos de comunicación rápidas e inmediatas, contradictoriamente, las sociedades viven internamente una ampliación de distancias y barreras sociales y culturales entre sus segmentos y grupos: procesos de incomunicación social, actitudes de intolerancia y racismo, miedos sociales, son algunos de los fenómenos que extrapolan las relaciones personales o las esferas socioculturales. Ellas desafian y bloquean la vida asociativa y política contemporanea dificultando los procesos participativos y la arena de la negociación democrática. El surgimiento de nuevos actores - mediadores, complementando o sustituyendo los mediadores políticos clásicos (jefes y representantes políticos, partidos, sindicatos, etc.), responden a esas nuevas necesidades de tránsito e interlocución entre mundos diferentes y, principalmente, material y simbólicamente desiguales, en el interior de las sociedades. Así, ya sea en el campo de la cultura, ya sea en el de la política y acción social, hoy despunta toda una serie de actores individuales y de la Sociedad Civil organizada 
(ONGs, asociaciones, movimientos de usuarios y consumidores, grupos culturales, etc.). Son actores con capacidad de circular socialmente y, comprendiendo diferentes códigos, valores y realidades, colaboran en la interpretación y en la denuncia social de las desigualdades y en la traducción de las diferencias. Se debe destacar que, desde un punto de vista más político, esos mediadores, aunque dispongan de legitimidad frente a los diferentes grupos y segmentos sociales, no se proponen a representarlos políticamente. Entretanto, en muchos casos, su acción está direccionada tanto para la defensa de causas y derechos, como para la recepción, calificación y traducción de demandas en proyectos sociales.

El Asistente Social es uno de esos profesionales-mediadores. Por mayores que hayan sido las alteraciones experimentadas en la condición del ejercicio profesional, nuestro oficio permanece marcado por el tránsito entre realidades sociales diferentes $\mathbf{y}$ desiguales. Las transformaciones contemporáneas, con sus dilemas y posibilidades, colocan como desafio profesional la necesidad de nuevas interpretaciones y nuevos indicadores a través de los cuales nuestra intervensión profesional pueda ser comprendida teóricamente y construida empiricamente.

\section{La Ciudadanía como Indicador para la Acción Profesional}

La construcción del ejercicio profesional tiene que hacerse, obviamente, a partir de las diferentes transformaciones sociales vividas en el mundo contemporaneo, con sus dilemas y posibilidades, lo cual coloca nuevos desafios, ya sea a nivel de los instrumentos teóricos de análisis, ya sea a nivel empírico, donde los conflictos $y$ potencialidades de nuestras sociedades constituyen la materia prima que nos es impuesta y que debemos obligatoriamente considerar.

Si se puede decir que el siglo XIX fue caracterizado por la costrucción de los Estados Modernos y el siglo XX configuró, más nitidamente, las Naciones, el siglo XXI tendría como meta la construcción de las Sociedades, hoy dilaceradas por profundas desigualdades económicas, políticas y socio-culturales.

Combatir las desigualdades, recolocar la Igualdad y la Justicia Social, constituyen pues, las tareas que convocan los diferentes sectores de la sociedad, y nuestro propio segmento profesional, para su enfrentamiento, en este nuevo siglo. En esta perspectiva la construcción de la Ciudadanía es retomada y adquiere relevancia. ¿Qué significa hoy construir la ciudadanía y cuál es el 
significado de ser ciudadano?

Desde un punto de vista más general, en un contexto de desigualdades, la ciudadanía exigiría ser económicamente inclusiva, fortalecedora de lazos y vínculos sociales y receptora de lo culturalmente diverso.

Por otro lado, ser ciudadano en el mundo contemporaneo, significa, en términos substantivos, pertenecer a una colectividad organizada según determinadas creencias, normas y procedimientos que coordinen la acción común y las acciones individuales para afrontar problemas y conflictos, con respecto al espacio y a la esfera colectiva (Thiebaut; 1998). Ser ciudadano es por tanto, pertenecer y sustentar, aunque críticamente, esas creencias y normas y también modificarlas y alterarlas una vez que "el pertenecimiento ciudadano" no es pasivo. Al contrario, la ciudadanía implica una postura activa, de ejercicio, de elecciones y de intervención en diferentes instancias de la sociedad. Esa participación directa, o a través de mediaciones institucionales, "en aquello que es hecho socialmente", señala el proceso de construcción del ciudadano: "El ciudadano se hace, haciendo su sociedad".

Considerando que una de las dimensiones fundamentales de la ciudadanía es su ejercicio, se torna importante la consideración, desde el punto de vista de la sociedad, de las condiciones y garantías que deben ser constantemente creadas y recreadas a nivel de las instituciones y de los derechos para viabilizar esa participación ciudadana. Desde el punto de vista de los individuos, el formar parte y el actuar implican un domínio mínimo de códigos, símbolos y signos de la sociedad de tal forma que puedan expresar sus motivaciones y demandas, y moverse, accesando y utilizando los recursos de su colectividad y contemporaneidad.

Además, hoy el concepto de ciudadanía, de cierta forma, viene recuperando la noción de Comunidad. Pero, no se trata de una comunidad homogénea o de un formar parte articulado por los orígenes y destinos comunes, como suponían los comunitaristas. Se trata de una noción de Comunidad Compleja marcada por diferencias y desigualdades y por una pluralidad de arreglos normativos entre los cuales los individuos deben optar. Obviamente, hay referentes comunes, elementos civilizatorios y grados de institucionalización, ya alcanzados, vinculados a las diferentes generaciones y grupos. Entretanto, para el sujeto contemporaneo, las creencias no se revisten de carácter absoluto, ni sus principios morales asumen un significado único e inmutable. Esa posibilidad de un doble o múltiples registros y de encontrarse con lógicas de operación distintas, y a veces 
hasta conflictivas, marca la condición de pertenencia y la reflexión del individuo contemporaneo.

Esas características se tornan más graves cuando, en sociedades marcadas por desigualdades, son focalizados grupos sociales más pobres, grupos étnicos, o segmentos de jóvenes cuyas condiciones y modos de vida están más distantes y cuestionan los tipos dominantes. Aquí, las desigualdades y diferencias terminan construyendo sistemas éticos dualistas que, orientando la acción de los individuos y grupos, imponen barreras y desafíos a la construcción de múltiplos comunes que puedan movilizar a la sociedad y darle sentido a la ciudadanía.

La construcción de la ciudadanía como proceso social más amplio y como elemento de orientación del quehacer profesional implica, por tanto:

- Pensar las desigualdades como una condición a ser radicalmente combatida y superada;

- Considerar a los individuos como sujetos de derechos, por tanto reflexivos y activos en las formas de concebir y enfrentar tanto sus condiciones de existencia, como sus prácticas de acción colectiva;

- Comprender y aceptar las diferencias sociales, culturales y subjetivas a partir de lo que ellas representan de diversidad, de dinamismo y de riqueza social;

- Incorporar la tolerancia como elemento fundamenetal en la ecualización de las diferencias y en el enfrentamiento de las discriminaciones que impiden el ejercicio de la ciudadania;

- Considerar las comunidades, y otras esferas marcadas por relaciones primarias, como espacios sociales fundamentales de localización social de los individuos, de construcción de identidades, lealtades y posibilidades de construir virtudes cívicas;

- Ampliar las virtudes y orientaciones de acción más local para la esfera pública a través de la afirmación de determinados valores y perspectivas que tengan sentido de múltiplos comunes. Aquí pueden considerarse tanto lógicas construidas de acuerdo a la experiencia historica y actual de las diferentes sociedades y sus grupos internos, como aquellas extraidas de la afirmación minimalista de determinados valores que hoy pueden ser considerados como parte del patrimonio occidental -y quizá, universal- del género humano tales como: el valor de la Vida, de la Paz, de la Justicia, de los Derechos Humanos, de la preservación de la Naturaleza, etc.

Estos elementos, que están presentes en una perspectiva de ciudadania son, a 
nuestro entender, los que deben presidir a la construcción de políticas sociales y su análisis a través de indicadores. Lo que estamos llamando Indicadores sociales para la Ciudadanía es precisamente eso. Se trata de la construcción de parámetros a través de los cuales se pueda apreciar la contribución que determinadas políticas dan al avance de esos procesos en nuestras sociedades.

Las concepciones más usuales de indicadores se refieren al uso de medidas, en general, escalas numéricas (estadísticas) o escalas de clasificación (muy bueno, bueno, regular, aceptable/inaceptable, etc.), que buscan medir la magnitud de los fenómenos comparándolos a un padrón establecido. Ese padrón, en el caso de las políticas sociales, es construido con referencia a una meta a alcanzar, cuya mayor o menor aproximación determina el éxito o el fracaso de la política o acción analizada.

La lógica que comanda la construcción de los indicadores de evaluación gira en torno de la uniformización de las fuentes de datos, de la homogeneización de los informantes, de las posibilidades de informatización de elementos que permitan medir la eficacia, eficiencia y productividad de las políticas o acciones sociales en relación a metas establecidas. Esas son formuladas y formateadas por los planificadores y/o financiadores, donde la cuestión de la validez estará dada por la capacidad de la experiencia de corresponder, en mayor o menor grado, a los criterios establecidos.

Esa forma de operación, fuertemente homogeneizadora, se fundamenta, en gran parte de los casos, en una postura externa, en relación a los grupos atendidos (su historia, su cultura, sus diferencias y potencialidades), donde se desconsidera las informaciones que escapan de la "grilla" de los parámetros establecidos. Con esto, se excluye la posibilidad de contemplar otros tipos de logros alcanzados por la población y por la propia política analizada.

Esa situación toca al profesional de Servicio Social de forma nítida. El hecho de no establecer indicadores sociales para su actuación profesional o simplemente someterse a los que le son propuestos - o impuestos - por parte de las instituciones, instancias gubernamentales y órganos financiadores, hacen que el profesional vea limitadas las posibilidades de una evaluación más rica de su trabajo y restrinja las apreciaciones de su contribución en los procesos y movimientos más amplios de la sociedad.

Nuestra propuesta es, por tanto, tomar como meta la construcción de la sociedad y como indicadores los elementos que caracterizan la ampliación de la ciudadanía en el mundo contemporaneo. 
Nuestra tarea será especificar, en cada realidad de intervención, aquellas dimensiones que nos permitan evaluar y medir los avances y retrocesos que, a partir de una situación inicial dada, consigamos obtener en ese proceso.

Esto significa definir indicadores que apunten o demuestren en que medida, considerando las realidades nacionales, institucionales y de los individuos y grupos atendidos, las intervenciones realizadas consiguieron contribuir a:

- La inclusión económica de los individuos;

- El fortalecimiento de vínculos y lazos sociales;

- La comprensión y el desarrollo de la tolerancia en relación a las diferencias;

- La ampliación de la reflexibilidad de los sujetos, de las nociones de derecho, y de la formación de criterios frente a ordenes normativas distintas y conflictivas;

- El aumento del domínio de lenguajes, códigos de significación y recursos institucionales que circulan socialmente;

- La ampliación del conocimiento y del sentido crítico en relación a sus comunidades de referencia;

- La reducción del aislamiento social;

- El aumento de la participación en distintas formas de acciones e instituciones colectivas civiles, ya sean sociales, culturales o políticas;

- La identificación de múltiplos comunes por los cuales, ultrapasando particularismos y localismos, los individuos y grupos puedan articular su actuación en la esfera pública y en los espacios colectivos.

Esas son todas las dimensiones posibles, y socialmente necesarias, para que la profesión se inserte en el horizonte de construcción de la ciudadanía para alcanzar sociedades más justas, humanas y democráticas.

\section{BIBLIOGRAFÍA}

CANDAU, Vera Maria - "Identidade Latino-Americana e Globalização" in Vera M. Candau e Susana Sacavino ( org.) Educar em Direitos Humanos: Construir a Democracia. Rio de Janeiro, DP\& A, 2000.

CARVAlHo, José Murilo- "Cidadania: Tipos e Percursos" in Revista de Estudos Históricos. Rio de Janeiro, vol. 18- n 18, 1996.

Horizonte, Ed. UFMG, 2000

- "Cidadania na Encruzilhada" in Newton Bignotto ( org.) Pensar a República. Belo

HABERMAS, Jürgen - A Inclusão do Outro: estudos de teoria política. São Paulo, Ed. Loyola, 2002.

Palobra No. 6 Agosto/2005 
HALL, Stuart- Identidades Culturais na Pós-Modernidade. Rio de Janeiro, DP\&A, 1999.

MARAZZI, Christian - "A Crise da New Economy e o trabalho das multidões" in Giuseppe Cocco, Graciela Hopstein (orgs.) As Multidões e o Império: entre globalização da guerra e universalização dos direitos. Rio de Janeiro, DP\&A, 2002.

MARSHALL, T. H. Ciudadania, classes e status. Rio de Janeiro. Ed. Jorge Zahar, 1965.

MINISTÉRIO DA JUSTIÇA / SEC. NAC. DIREITOS HUMANOS / PNUD / USP- "Os Jovens e os Direitos Humanos" - Relatório da Cidadania. Brasília, 2002.

OLIVEIRA, Francisco - "O Que É Formação para a Cidadania"- entrevista a Silvio Caccia Bava in Pólis (Instituto de Estudos, Assessoria e Formação em Políticas Sociais). São Paulo, agosto, 2000.

PANDOLFI, Dulce C. et. alii. (orgs.) - "Cidadania, Justiça e Violência". Rio de Janeiro. Fund. Getúlio Vargas, 1999.

ROBERTS, Bryan - "A Dimensão Social da Cidadania" in Rev. Bras. De Ciências Sociais. São Paulo. ANPOCS, no 33, Ano 12, fev.1997.

SANTOS, Boaventura Sousa - Reinventar a Democracia. Lisboa, Ed. Gradiva, 1998.

THIEBAUT, Carlos - Vindicación del ciudadano: un sujeto reflexivo. Barcelona. Ed. Paidós, 1998.

TURNER, Bryan - "Outline of a Theory of Citizenship". Chicago: Sociology, 24. 2, 1990.

VIANA, Luiz Werneck e CARVALHO, Maria Alice Rezende - "República e Civilização Brasileira" in Pensar a República. Belo Horizonte, Ed. UFMG, 2000.

WALZER, Michael - Tratado sobre la Tolerancia. Buenos Aires, Ed. Paidós,1998.

\section{BIOGRAFÍA}

\section{ANA MARÍA QUIROGA}

Asistente Social, Doctora en Antopología E.H.E.S.S. Paris, coordinadora de la línea de investigación "Religión y Sociedad Civil" en el Instituto de Estudios de Religión. Río de Janeiro, Brasil. 